\title{
Suling Dewa dalam upacara Ngaponin Suku Sasak
}

\author{
Muhammad Arsyad Nur Kholis ${ }^{1}$
}

\begin{abstract}
Suling Dewa is a very distinctive art and became the identity of Sasak Lombok Ethnic. This art stores a variety of uniqueness and that is you can't found in other areas, one of which is the interval of the tone and the lyrics are so contrasting. This art consists only of two players a vocalist and one flute players. In each of the elements in theSuling Dewa Sasak have the meaning of soul from the mirroring of Sasaknese ethnic identity. This distinctive art in its existence in society is widely used in various sacred rituals and ceremonies. One of Suling Dewa functions is used in Ngaponin ceremony or clean up the old metal ceremony every four years. In Ngaponin ceremony series there is one mandatory procession called as Mendewa. The fungtions of Mendewa procession is called the metaphysical object for making the energy wall of guard. Islam Metu Telu is a belief system in Lombok society. This belief system the majority people life in north of Lombok island and the minority you can find that in all areas of Lombok Island. A beautiful combination pattern is contained in the teachings of Islam Metu Telu or also known as Wetu Telu and WaktuTelu. The combination in question is a pattern of syncretism between religions and cultures that are so harmony that so maintained by society. The presentation of Suling Dewa in Ngaponin ceremony consists of two aspects, the textual and contextual. The textual aspect consists of musical events such as gending, music instrument, lyrics of vocal mantra, instrumental organology and contextual aspects including non-musical events consisting of time, place and other ceremonial processions. Suling Dewa to this day is a primary item in a ceremony or a specific ritual that uses Suling Dewa. Any ceremonies and rituals that use Suling Dewa can't be done without the presence of the Suling Dewa artist. This proves give the concluses the Suling Dewa have a important position in the life of Sasak Kuto - kute community.
\end{abstract}

Keywords: Suling Dewa, Ngaponin, Islam Metu Telu

\begin{abstract}
Abstrak
Suling Dewa adalah kesenian yang sangat khas dan menjadi identitas Suku Sasak Lombok. Kesenian ini menyimpan beragam keunikan yang tidak dijumpai di daerah lain, salah satunya adalah interval nadanya (panteg/bukaan) dan liriknya(base inan gending) yang begitu kontras. Kesenian ini hanya terdiri dari
\end{abstract}

${ }^{1}$ Mahasiswa Jurusan Etnomusikologi FSP ISI Yogyakarta. 
dua orang pemain yaitu vokalis dan peniup seruling. Dalam setiap unsur - unsur yang ada di dalam Suling Dewa Suku Sasak Kuto - kute terdapat makna yang begitu mendalam sebagai cerminan jati diri Suku Sasak.Kesenian khas ini dalam keberadaannya di masyarakat banyak digunakan dalam berbagai macam ritual dan upacara sakral. Salah satu fungsi Suling Dewa adalah digunakan dalam upacara Ngaponin atau upacara pensucian pusaka setiap empat tahun sekali.Dalam rangkaian upacara Ngaponin terdapat salah satu prosesi wajib yang disebut sebagai Mendewa. Prosesi Mendewa adalah kegiatan memanggil mahluk supernatural dengan menggunakan Suling Dewa dan mantranya. Mendewa dalam upacara Ngaponin memiliki fungsi yaitu menghadirkan dinding supernatural untuk melindungi pusaka yang disucikan agar terhindar dari energi - energi negatif. Islam Metu Telu adalah aliran kepercayaan masyarakat Lombok. kepercayaan ini sebagian besar berada di tanah Bayan dan sebagian lainnya tersebar di seluruh Pulau Lombok. Sebuah pola kombinasi yang indah terkandung dalam ajaran Islam Metu Telu atau yang juga dikenal dengan sebutan Wetu Telu dan Waktu Telu. Kombinasi yang dimaksud adalah pola sinkretisme antara agama dan budaya yang begitu harmoni dan begitu dijaga oleh masyarakat.Penyajian Suling Dewa dalam upacara Ngaponin terdiri dari dari dua aspek yaitu tekstual dan kontekstual. Aspek tekstual terdiri dari kejadian intramusikal seperti gending, seruling, lirik mantra vokal, organologi instrumen serta aspek kontekstual meliputi kejadian ekstramusikal yang terdiri dari waktu, tempat dan prosesi - prosesi upacara lainnya. Suling Dewa hingga saat ini merupakan kebutuhan primer dalam upacara atau ritual tertentu yang menggunakan Suling Dewa. Setiap upacara dan ritual yang menggunakan Suling Dewa tidak akan dapat dilakukan tanpa adanya kehadiran seniman Suling Dewa itu sendiri. Hal ini membuktikan bahwa Suling Dewa memiliki kedudukan yang penting dalam kehidupan masyarakat adat Sasak Kuto - kute.

Kata Kunci : Suling Dewa, Ngaponin, Islam Metu Telu

\section{Pendahuluan}

Kabupaten Lombok Utara Provinsi Nusa Tenggara Barat merupakan salah satu pulau dan daerah yang terletak di bagian tengah Indonesia dengan penduduk mayoritas beragama Islam. Antara adat lama dan ajaran Islam di daerah ini sangat begitu kontras, adat istiadat yang berornamenkan Hindu Majapahit serta animisme, dinamismesedang agama Islam dengan khaidah - khaidah keislamannya yang mengakar masih terus lestari dengan pola yang unik.

Bayan adalah desa terpencil di Lombok Utara dengan masyarakat adat Sasak yang masih memegang kuat aturan tradisinya. Dengan pembagian sub suku Sasak 
menjadi empat yaitu Meno - mene (Lombok Barat), Kuto - Kute (Lombok Utara), Meriyak - meriku (Lombok Selatan) dan Ngeno - ngeni (Lombok Timur) tentulah masyarakat Bayan tergolong dalam sub Kuto - Kute. Masyarakat Sasak di Bayan mayoritas memegang paham Islam Metu Telu, meski sejak tahun 1970 terlapor para migrans Muslim ortodoks (Islam umum) yang kehidupan sosial budayanya berbeda dengan orang Bayan melakukan pendakwahan dan menanamkan paham mereka atas sebagaimana Islam sesuai paham mereka. Namun hal demikian tidak berpengaruh danmenggoyahkan keyakinan akan masyarakat Bayan yang mempertahankan warisan Islam nenek moyang suku Sasak (Barton, Greg and Greg Fealy, 1981:170).

Suling Dewa dalam upacaraNgaponin adalah bentuk kegiatan adat yang masih dijalankan oleh masyrakat Bayan hingga saat ini. Proses kesenian ini mencerminkan idealisme dan pola sinkretisme masyarakat Sasak Wetu Telu yaitu membakar dupa, kemenyan, bunga rampe, serta pakain adat yang merupakan warisan Hindu sedang berdoa dan mempercayai keberhasilan ritual yang erat kaitannya dengan ruh nenek moyang dengan benda - benda yang dipercayai memiliki kekuatan magis adalah warisan animisme dan dinamisme Boda(agama asli Suku Sasak) dan terakhir adalah bacaan yang digunakan adalah bacaan ayat suci $\mathrm{Al}$ - qur'an sebagai pengaruh Islam. Hal ini merupakan gambaran masyarakat Sasak yang kuat akan nilai - nilai tradisi mereka secara turun temurun.

Ngaponin sebagai kontekstual atau peristiwa ekstramusikal merupakan pasangan yang tak dapat dipisahkan dari Suling Dewa sebagai peristiwa tekstual atau intramusikal. Suling Dewa sebagai instrumen pusaka diyakini oleh masyarakat setempat sebagai instrumen yang mampu menghadirkan energi supernatural guna mencapai tujuan keberhasilan upacara Ngaponin. Mitologi yang berkaitan dengan keharmonisan demi keberlangsungan hidup manusia selalu diciptakan oleh manusia itu sendiri guna menjaga keberlangsungan keseimbangan (Roland Barthes, 1983:89). Oleh sebab itu terciptalah Suling Dewa sebagai instrumen yang digunakan untuk memanggil opsatau energi - energi supernatural mana kala terjadi kesenjangan antara harapan dan kenyataan dalam kehidupan masyarakat Sasak Bayan. 


\section{Kehidupan Suku Sasak}

Islam merupakan agama yang memiliki khaidah - khaidah atau aturan - aturan yang telah disepakati dalam pemahaman masyarakat umum akan tafsir hadist dan kitab suci Al - qur'an. Namun ilmu tafsir masyarakat Bayan berbeda dengan masyarakat di luar Bayan pada umumnya. Seperti halnya genresalafi, sunni, sufi dan lainnya, mereka menyebut Islam mereka sebagai Metu Telu atau yang juga dikenal oleh masyarakat Sasak dengan istilah Waktu Telu dan Wetu Telu. Sejatinya ketiga istilah yang beredar di masyarakat yaitu Metu Telu, Wetu Telu dan Waktu Telu adalah sebuah sinonim yang dituju untuk genre Islam suku Sasak.

Masyarakat Pulau Lombok umumnya menganggap bahwa Islam Metu Telu merupakan ajaran yang bertentangan dengan syariat - syariat Islam dikarenakan oleh kurangnya pemahaman mereka akan Islam Metu Telu dan menggunakan standar ideal Islam sebagai standar komparasi. Hal yang paling umum tentang tudingan masyarakat Metu Telu adalah ibadah shalat mereka yang hanya tiga kali saja dalam satu hari dan beberapa pelanggaran fundamental lainnya. Hal tersebut alhasil membuat beberapa masyarakat umum berupaya untuk mentransformasikan manifestasi praktek agama Islam general yang dianggap standar kepada masyarakat Sasak Lombok Utara.

Metu telu dalam prespektif kulturisme pasti akan berbeda hasilnya dibanding prespektif konseptualis doktrinal, dogma dan generalisasi theisme. Karena hanya dengan melihat dari prespektif kulturisme kita dapat memfilterisasi kesenjangan jarak antara manifestasi dogma agama ,norma - norma kitab suci dan pola pikir masyarakat.

Islam Metu Telu bagi masyarakat adat merupakan konsep ideologi dan filosofi kehidupan, namun dengan pola sinkretisme yang tertanam dalam kegiatan masyarakat adat membuat tercipta kesepakatan istilah Metu Telu dalam masyarakat sebagai aliran atau genre yang merujuk pada masyarakat Islam Bayan / Islam khas suku Sasak. Meski demikian tidak ada seorang pun yang mengetahui kapan istilah Metu Telu lahir dan digunakan dalam kehidupan sehari - hari (Ma Lokaq Walin Gumi, Trantapan Bayan. 23 April 2017). Namun banyak pemikiran yang menjelaskan bahwa pola ini lahir akibat pengislamannya yang belum selesai dimasa lalu. Para wali yang dulu berdakwah menyebarkan Islam di Pulau Lombok, datang melalui pelabuhan Carik yang berada di 
wilayah Bayan. Pengislaman tersebut hanya berlangsung dalam waktu yang singkat dikarenakan para wali tersebut akan melanjutkan perjalanannya ke wilayah Lombok lainnya dan Pulau Sumbawa. Alhasil hanya masyarakat pria saja yang memeluk agama Islam, sedang kaum wanita masih memegang ajaran Hindu Majapahit. Pergesekan kepercayaan kaum wanita dan pria ini terjadi dalam jangka waktu yang cukup panjang dan menyebabkan lahirnya pola sinkretisme yang kini kokoh di tanah Bayan (pemahaman masyarakat Sasak umum di Pulau Lombok).

Masyarakat Metu telu memiliki sistem - sistem kosmologis sendiri, pengetahuan agama dan tradisi yang begitu khas. Mereka juga memiliki pemuka - pemuka yang legitimate ditanah Bayan dalam konteks adat spritualis yaitu: Ma Lokaq Pande Karang Bajo, Ma Lokaq WalinGumi Trantapan, Penghulu Adat Agung, Kiyai, dan Pembekel. Status tertinggi dipegang oleh Ma Lokaq Pande dan Ma Lokaq Walin Gumi. Kedua tetua adat ini memiliki kelebihan khusus dibanding Ma Lokaq(Ma Lokaq merupakan gelar kehormatan yang diberikan kepada seseorang yang memiliki peran khusus "the role") lainnya. Kelebihan kedua pemimpin ini antara lain seperti, melepas jabatan $M a$ Lokaq, memberhentikan proses ritual, dipilih hanya melalui rapat internal keluarga (tanpa dinobatkan melalui pilihan masyarakat umum), kehadirannya merupakan syarat mutlak berjalannya sebuah ritual (Kake Sutyadi, Karang Bajo Bayan, 23 April 2017) dan selain itu masih banyak lagi kelebihan Ma Lokaq Pande dan Ma Lokaq Walin Gumi. Sebagai pemimpin spiritualis Ma Lokaq Pande mengatakan kalau ada masyarakat mengatakan Metu Telu sebagai 'waktu tiga' dan mengaitkan dengan mendistorsikan seluruh ibadah Islam menjadi tiga, hal tersebut tidak benar adanya ( $M a$ Lokaq Pande, Brugaq Lokaq Pande Karang Bajo, 22 April 2017).

Menarik garis tengah dari versi pendapat masyarakat yang beredar, dapat diartikan pula jika Wetu dan Metu merupakan sebuah kehadiran di dunia, Waktu sebagai arti sebuah masa atau era dan Telu sebagai tiga buah objek yang berkaitan dengan Wetu,Waktu dan Metu. Sehingga Telu atau tiga menjadi misteri dan sebuah pertanyaan. Apa ketiga objek yang berkaitan dengan Waktu,Metu dan Wetu? Dengan kata kunci dari tidak ada menjadi ada, tumbuh berkembang dan memiliki masa atau era di Gumi Sasak. Atas rumusan di atas dapat ditarik kesimpulan ketiga objek tersebut adalah Boda, Hindu 
dan Islam. Hal ini dikatan seperti demikian dengan alasan melihat fenomena sinkretisme di masyarakat yang tercermin melalui keyakinan masyarakat akan benda - benda yang memiliki kekuatan (Boda), berdoa melalui media perantara dupa dan sesajian lainnya (Hindu) dan menggunakan ayat suci Al - qur'an sebagai mantranya (Islam). Proses ini bukanlah suatu hal yang negatif, menurut penulis proses ini membuktikan bahwa masyarakat Bayan merupakan masyarakat yang sangat arif dan menghargai warisan warisan yang pernah tumbuh dan lahir di Gumi Bayan. Bentuk dampak positifyang nyatapun dapat kita lihat dalam cerminan lingkungan Bayan yang tentram dan jauh dari bentuk pelanggaran - pelanggaran yang merugikan sosial.

Kekayaan masyarakat Metu Telu merupakan kekayaan adat yang harus kita jaga bersama. Kekayaan yang dimaksud di sini adalah kekayaan yang merujuk pada sistem sistem pranata adat yang meliputi seni dan budaya. Masyarakat Metu Telu yang sebagian besar adalah suku Sasak komunal Kuto - kute memiliki multi dimensi kesenian diantaranya yaitu : 1) gambus penting (sound), 2) gegeroq tandaq (gerak), 3) cupak gerantang (drama), 3) seseq (menggambar ornamen dengan rajutan benang), 4) tatah (kriya ukir), 4) takepan (sastra) dan lain sebagainya.

\section{Suling Dewa Pada Suku Sasak}

Pandangan ekologis menyatakan bahwa informasi perseptual mengenai 'persepsi dan aksi' merupakan mata rantai yang tak terpisahkan. Oleh sebab itu interaksi antar individu, kelompok dan lingkungan akan menghasilkan media komunikasi (Djohan, 2010:10). Menurut Lund, salah satu media sebagai hasil interaksi manusia dengan lingkungannya adalah alat - alat bunyi (C. Lund, The Archaeomusicology of Scandinavia dalam World Archaeology 12, 1981:246 - 265). Suling Dewa sebagai alat musik sakral suku Sasak Kuto - Kute dalam aplikasinya sangat relevan dengan perkataan para ahli diatas mengenai musik sebagai media interaksi. Ketika ada interaksi berarti ada sebuah komunikasi yang ingin disampaikan. Komunikasi yang dimaksud disini adalah komunikasi menggunakan bahasa musik atau dapat juga dikatakan sebagai makna yang terkandung melalui syair, instrumen, komposisi musik dan unsur - unsur intramusikal lainnya. 
Kedudukan Suling Dewa sebagai teks tidak terpisahkan dengan konteks. Shin Nakagawa mengatakan pengertian teks dalam musik adalah kejadian akustik, sedangkan konteks adalah suasana, yaitu keadaan yang dikondisikan oleh masyarakat pendukung musik tersebut. Etnomusikologi menggunakan pengertian teks melalui analisis konteks atau menghubungkan pengertian teks dengan konteks (Shin Nakagawa, 2000:6). Mengacu pada pernyataan itu menurut I Wayan Senen peristiwa teks dalam pertunjukan bunyi - bunyian ritual meliputi: pelaku, syair, instrumen, lagu, tempat, dan penikmat (I Wayan Senen, 2015:102). Seiring dengan pernyataan tersebut pembahasan peristiwa musikal Suling Dewa dalam upacara Ngaponin terurai sebagai berikut.

1) Pelaku

a) Peniup Seruling Jero Gamel

Peniup Suling Dewa diberi gelar kehormatan oleh masyarakat setempat dengan julukan Jero Gamel yang artinya adalah pemain musik yang berkedudukan tinggi atau berstrata tinggi. Peniup Suling Dewa ini diwajibkan adalah orang tua yang berumur lima puluh tahun keatas.

b) Pelantun suara Inan Gending

Inan Gending merupakan gelar kehormatan yang diberikan kepada vocalist Suling Dewa. Secara terminologiInan Gending memiliki arti sebagai induk bunyi atau suara yang terstruktur. Standar atau syarat khusus untuk menjadi Inan Gending SulingDewa dalam upacara apapun (termasuk upacara Ngaponin) adalah wanita yang sudah berhenti menstruasi. Hal ini dikarenakan masyarakat begitu menjaga kesucian Suling Dewa, sehingga wanita yang memiliki kemungkinan menstruasi dilarang melantunkan mantra gending - gending Suling Dewa.

c) Pelantun suara mantra non melodis

Ma Lokaq Pande dan Ma Lokaq Walin Gumimerupakan pelantun mantra non melodis dalam upacara apapun (termasuk upacara Ngaponin). Fenomena ini terjadi akibat kedudukan keduanya yang begitu penting. Ma Lokaq Pande dipercayai sebagai juru kunci alam halus atau ghaib, sedangkan Ma Lokaq Walin Gumi dipercayai sebagai juru kunci alam nyata atau dunia. Atas tugasnya masing - masing maka mantra - 
mantra ghaib akan dilantunkan oleh Ma Lokaq Pande dan mantra - mantra dunia akan dilantunkan oleh Ma Lokaq Walin Gumi.

2) Syair

a) Syair mantra bepaudan

Syair mantra bepaudan adalah syair mantra bermelodi atau lirik gending. Suling Dewa memiliki empat puluh tiga gending sakral yang berlirik dan tiga diantaranya merupakan syair mantra yang wajib lantunkan dalam setiap upacara. Ketiga gending tersebut adalah lokoq sebie, pang pang poq dan lembuneng meloang.

b) Syair mantra nyaraq paudan

Syair mantra nyaraq paudan merupakan syair mantra yang non melodi. Syair mantra ini terdiri dari tiga jenis yaitu tabeq, sembeq dan amit - amitan. Tabeq merupakan syair mantra untuk menyampaikan sebuah permakluman atau secara harfiah berarti permohonan permisi, sedangkan sembeq merupakan syair mantra yang berarti pemberkatan dan yang terakhir amit - amitan adalah syair mantra penghormatan sebelum mengakhiri proses upacara. Meskipun tidak memiliki melodi namun syair mantra ini bersifat paten dalam aksen dan panjang pendek pembacaan kata - katanya. Berikut adalah transkrip mantra tabeq nyaraq paudan yang terinspirasi berdasarkan hukum harkat tajwid $\mathrm{Al}$ - qur'an.

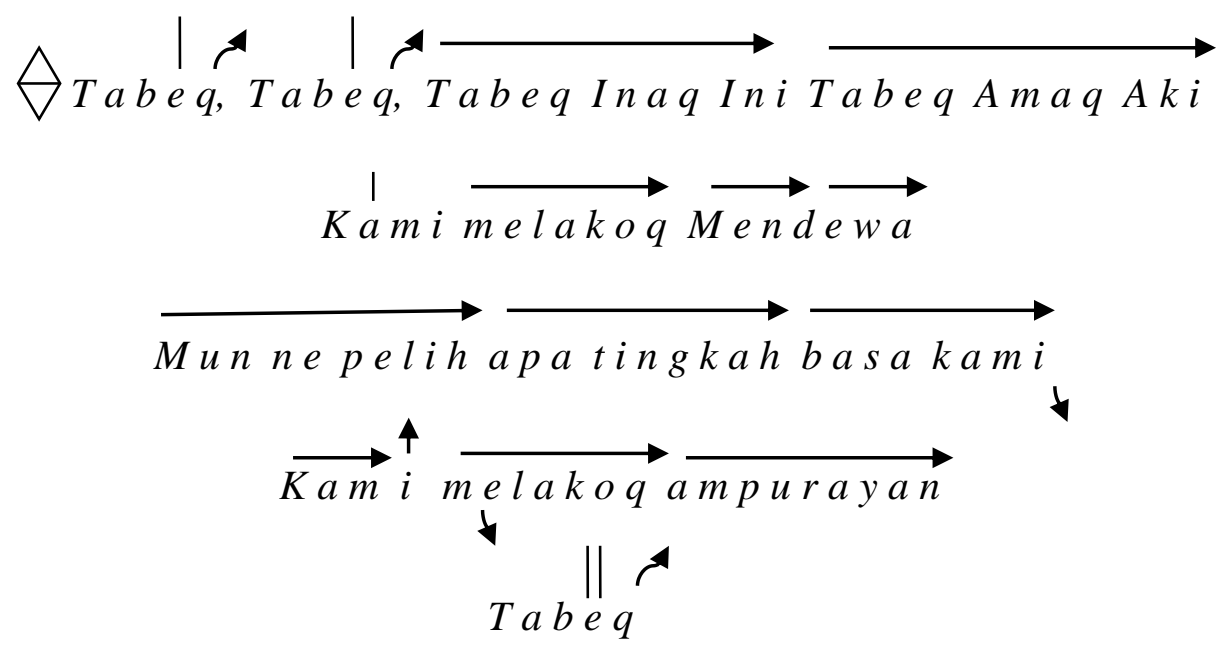

$\mathrm{FD}=$ Bebas, Tempo = Atempo 
Keterangan Simbol :

1) $\mathrm{FD}=$ Frekuensi dasar, bebas tergantung siapa yang membaca.

2) $\diamond=$ Suara lantang dan tegas, sebagai kode tehnik membaca

3) $\mid$ = Dibaca empat harkat atau empat nafas.

4) I = Dibaca dua harkat atau dua nafas.

5) = Suara dinaikkan dengan konsonan hambat atau mati.

6) $\longrightarrow=$ Dibaca cepat dan berhenti diujung panah.

7) $\downarrow=$ Intensitas atau power suara menurun

8) $\uparrow=$ Mengembalikan power intensitas suara seperti awal

9) $\|$ = Power diduakali lipatkan dan harkat sedikit dipanjangakan.

Notasi di atas jika dianalisis tampak aksen dan pola suara dari mantra Tabeq yang paten berhubungan dengan arti kalimat - kalimat yang diucapkan. Dalam bait pertama dilantunkan dengan nada tegas kalimat yang berarti mereka memohon kepada tetua - tua adat. Selanjutnya ketegasan suara dilanjutkan hingga bait kedua yang berarti mereka memohon melakukan upacara. Arti dari ketegasan - ketegasan tersebut menunjukan semangat dan kelugasan para pemohon yang berkobar - kobar dalam melakukan upacara. Selanjutnya dalam bait ketiga yang berarti jika ada kesalahan dari tingkah atau ucapan, power suara diturunkan di penghujung kalimat yang menunjukan bahwa manusia tidak luput dari kesalahan dan harus merendahkan diri. Bait keempat yang berarti memohon maaf power dilantangkan kembali, dengan maksut mereka akan selalu mengakui kesalahan dan berikrar memohon maaf yang sedalam dalamnya. Butir terakhir kelima adalah kelimaksnya mantra yang sangat power full mengartikan bahwa mereka siap secara utuh, sadar dan bertanggung jawab untuk melakukan upacara atau ritual.

\section{Instrumen}

Masyarakat Sasak Kuto - kute memiliki empat Suling Dewa sakral yang terpisah dalam empat wilayah mata angin desa adat yaitu utara, selatan, timur dan barat. Keempat Suling Dewa ini diberikan pengakuan yang kuat akan kesakralannya oleh 
masyarakat suku Sasak Bayan. Setiap bagian suling dipercaya memiliki makna dan maksud tertentu atas hubungannya dengan kepercayaan masyarakat. Berikut adalah gambaran organologi Suling Dewa beserta istilah - istilah lokalnya.

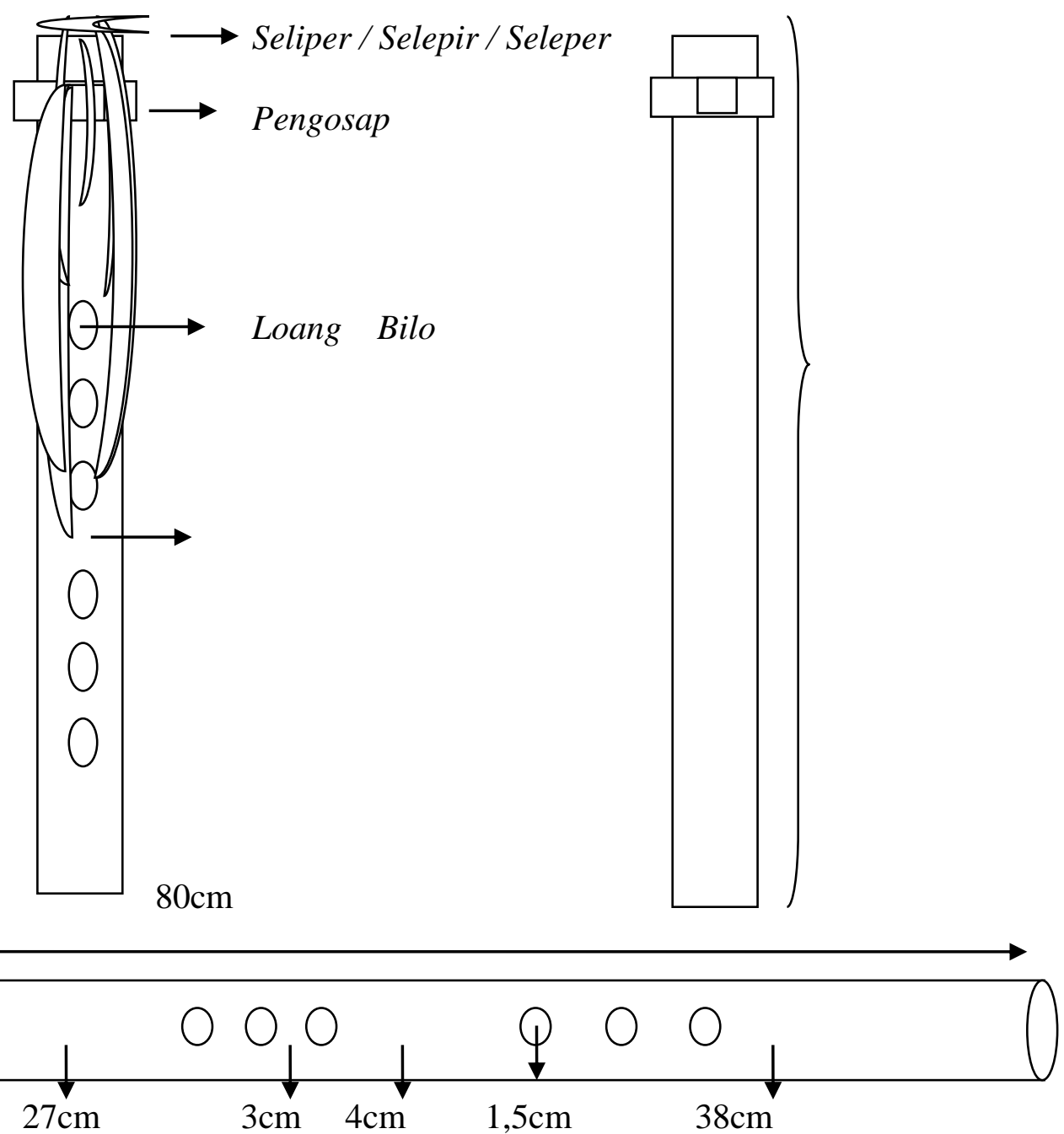

\section{Lagu}

Suling Dewa memiliki empat puluh empat lagu atau gending sakral. Empat puluh tiga diantaranya merupakan gending betembangan (memiliki lirik) dan gending bao daya sebagai satu - satunya gending nyaraq tembang (instrumental). Dari keseluruhan gending Suling Dewa, lembuneng meloang, lokoq sebie, pang pang poq 
dan bao daya tersebut merupakan gending paling sakral dan wajib dilantunkan dalam seluruh proses upacara.

Ngaponin sebagai upacara yang dilakukan empat tahun sekali merupakan upacara yang dianggap begitu khusus bagi masyarakat Sasak Kuto - kute. Perlakuan ini tercermin melalui syarat yang harus dilakukan masyarakat untuk menjalankan upacara Ngaponin, yaitu dengan mengumpulkan empat Suling Dewa yang di letakkan di empat sudut mata angin sekenem.Empat pemain Suling Dewa yang berada di empat mata angin ini akan memainkan gending bao daya terlebih dahulu secara bersamaan sebagai gending pembuka, selanjutnya disusul dengan tiga gending wajib lokoq sebie, pang pang poq, lembuneng meloangdan gending non wajib yang dipilih secara acak (rundom) dan dimainkan bergantian (Jero Gamel Anggalip, Telaga Banyaq. 25 April 2017). Berikut adalah transkrip notasi gending wajib lokoq sebie yang terinspirasi dari vocal atempo Jawa dan Bali salah satunya KidungDewa Yadna karangan Kak Agel (Kak Agel, 2003:1 - 50) beserta analisis motif dan kalimat musiknya.

\section{Lokoq Sebie}

Tempo : Bebas, Sukat : Bebas, Tonika : $354 \mathrm{~Hz}$

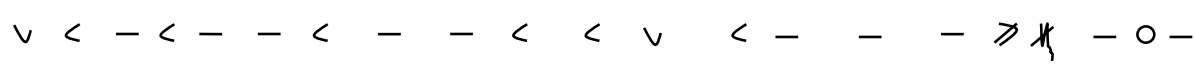

Ci ka yae nganaci ngando nae ngando rading nganando . . . .

$-\quad<0<<<v<v<0$

Nacinga nandoro ngandaee kayan .

$v---<v-0--<<<v-\wedge 0<v$

Nando kenae rading aro gilae knacinaro ngande .

$0<<<<0$ ov $<<<<0<v^{m}-0-0$

Ngae rongan ando nga era ngenando denda .ng . . . . . . .

O< v o < - o - < vovo < < o vo < -

Cinan naro nacinga nae ado de aro ngannna . . . .

- o- - - o - ov <-< o< o-

Ngana kna cinaro dando rana cika ya . . .

$<<0 v<v \stackrel{m}{n}$

Naro ngando ra ra ding

$\wedge O v<<<0<v v<v O-<v_{0} v<v_{0}<$ 
. E .gila na cingana na ado ro nganae .aka . . .

$<<<0 v<v v v v 0 v<v<0 v<v 0 n$

Ngana e ngandoorading aro gilae naci naro ngande. .

Istilah - istilah Simbol :
1) $\measuredangle=B a$
5) $>=T i$
9) / = Sepeleng
2) $\bigvee=L a$
6) $\eta=N i$
10) (O) = Bueq
3) $\bigcirc=T e$
7) $-=\mathrm{Ne}$
11) $ح=$ Nyelontag
4) $\wedge=D a$
8) $m=$ Ngijig
12) . = Teg

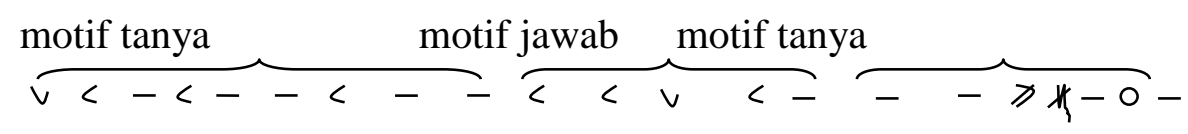

Ci ka yae nganaci ngando nae ngando rading nganando . . . .

\section{kalimat tanya}

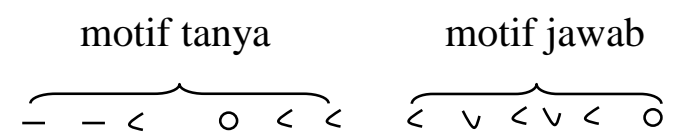

Nacinga nandoro ngandaee kayan

kalimat jawab

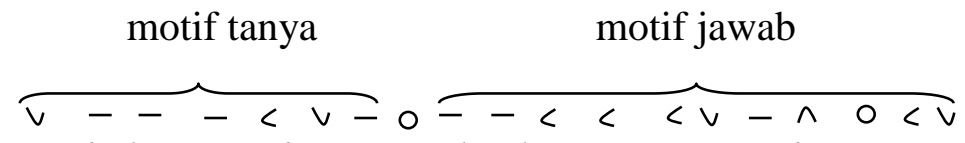

Nando kenae rading aro gilae knacinaro ngande .

kalimat jawab

motif jawab

motif jawab

motif tanya

$0<<<<0$ < $<<<0<0<v \wedge-0-0$ Ngae rongan ando nga era ngenando denda .ng . . . . . . . 


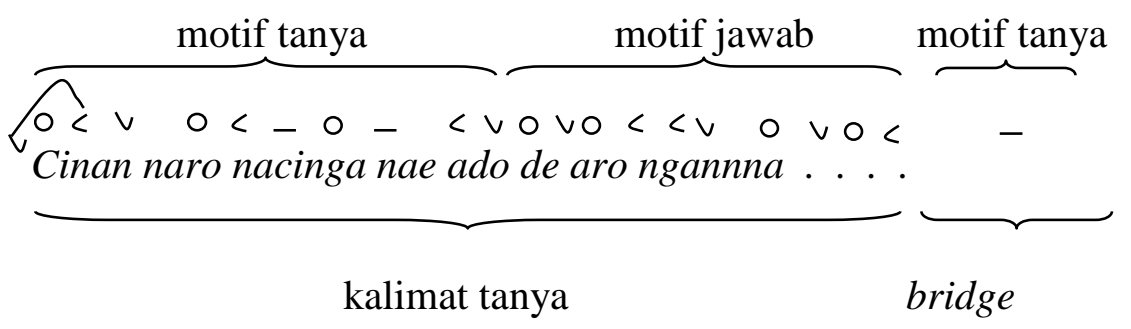

motif tanya motif tanya motif jawab motif tanya

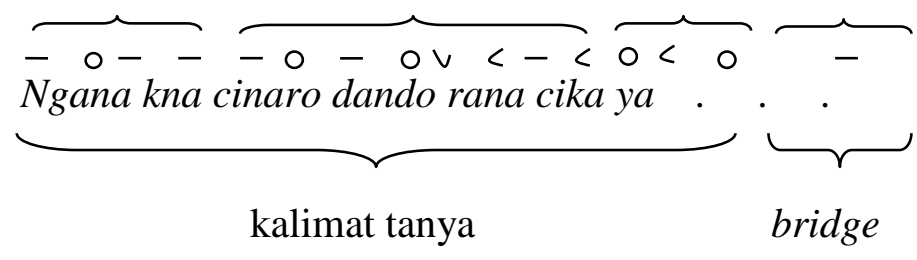

motif tanya motif jawab

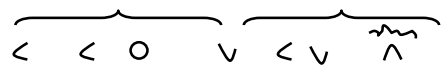

Naro ngando ra ra ding

kalimat jawab
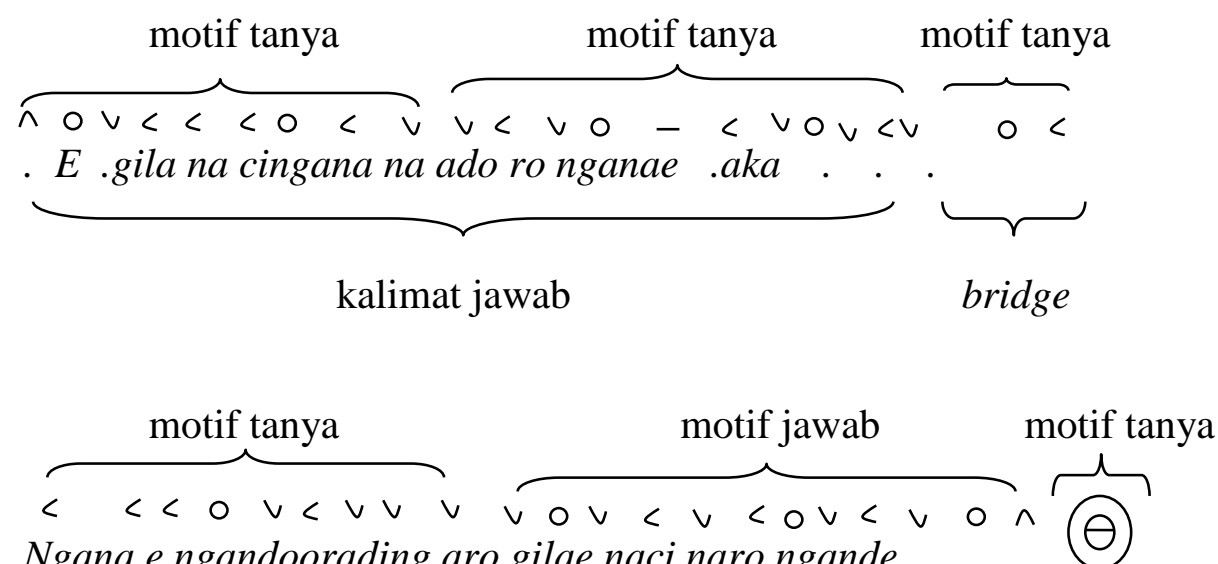

Ngana e ngandoorading aro gilae naci naro ngande. .

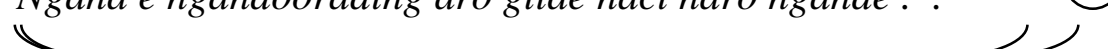

kalimat melodi vocal jawab

kalimat melodi Suling Dewa tanya 
Melihat dari analisis melodi di atas tampak keunikan dari gending lokoq sebieSuling Dewa adalah perbedaan kalimat penutup gending yang berupa kalimat jawab bagi vocal dan kalimat tanya bagi Suling Dewa. Keunikan ini terjadi pada empat gending wajib Suling Dewa. Seluruh bagian permainan Suling Dewa pada empat gending wajib akan berakhir di motif tanya dan kalimat tanya. Keunikan lainnya adalah setiap kalimat tanya pada permainan gending lokoq sebie akan diikuti oleh bridge atau jembatan melodi sebelum menuju kalimat selanjutnya, sedangkan kalimat jawab pada bait keempat adalah satu - satunya kalimat jawab yang menggunakan prolog atau ornamnetasi melodi diluar melodi pokok. Menimbang dengan jumlah sembilan bait yang ada di dalam gending lokoq sebie, adanya prolog dalam bait keempat gending lokoq sebie berfungsi sebagai penanda bahwa jalannya permainan musik atau gending akan memasuki tahap pertengahaan yaitu bait kelima.

Lokoq sebie adalah gending Suling Dewa yang digunakan untuk ritual pengobatan(Inan Gending Inaq Mutringen, Senaru, 24 April 2017). Lokoq sebie dipercaya mampu menghasilkan energi - energi kebaikan. Keuinikan lain dari gending ini adalah judulnya yang berarti sungai kering kerontang(Jero Gamel Nyakranom, Senaru, 24 April 2017) namun di tempatkan di posisi selatan yang di mana posisi selatan di tanah Bayan menunjuk pada Gunung Rinjani sebagai sumber air diseluruh Pulau Lombok. Alam semesta bukanlah mesin yang terbuat dari banyak objek, melainkan harmoni organis yang seluruh bagiannya dilihat melalui hubungan timbal balik diantara mereka(Fritjof Capra, 1984:56). Mengacu pada pernyataan tersebut adalah hal ini sangat ilmiah bahwa lokoq sebie berada di posisi selatan atau arah posisi Gunung Rinjani pada saat upacara Ngaponin berlangsung. Alasan terjadinya fenomena demikian adalah bahwa sains modern kini mengetahui bahwa setiap aliran sungai merupakan hasil dari pada air yang turun melalui pegunungan. Dan sehubungan dengan arti judulnya yaitu sungai yang kering bukan berarti tidak relevan antara air dan gunung. Karna tidak semata - mata sebuah judul menetukan isi kandungan mantra, arti sungai kering bukan berarti lantas gending lokoq sebie berisi doa manusia memohon agar sungai menjadi kering. Terkadang justru judul dan isi makna akan kontras, dapat dilihat contoh dalam kehidupan sehari - hari kita mengenal istilah doa kematian yang isinya 
terrnyata permohonan keselamatan selain itu kita mengenal doa bencana alam seperti gempa bumi, namun isi doanya bukan memohon bencana melainkan keselamatan dari bencana. Atas fenomena ini dapat disimpulkan bahwa gending lokoq sebie sejatinya merupakan doa agar Gunung Rinjani sebagai sumber air masyarakat, terus mengairi dan mengalir di seluruh sungai yang tampak. Makna gending lokoq sebie dan air yang tidak terpisahkan adalah sesuatu hal yang ilmiah jika masyarakat menganggap gending ini dapat menyembuhkan berbagai macam penyakit. Karna ilmu kedokteran pun membenarkan bahwa 90\% dalam tubuh manusia merupakan kandungan air. Selain itu setiap elemen memiliki sifat dasar masing - masing dan air (choleric) merupakan elemen yang mempunyai sifat memperbaiki, menyuburkan dan menyejukkan. Dalam ranah emosi, air dihubungkan dengan kasih sayang dan perasaan terdalam (Mary Bassano, John Beaulieu dan David McCann, 2015:150).

Suling Dewa merupakan instrumen sakral Suku Sasak yang hanya berjumlah empat buah dan digunakan saat upacara tertentu. Ngaponin adalah upacara pensucian pusaka empat tahunan masyarakat Bayan. Upacara ini menggunakan empat Suling Dewa yang di letakkan di empat arah mata angin guna menciptakan dinding ghaib saat pensucian pusaka. Oleh karena kedudukan dan fungsinya, hingga saat ini Suling Dewa begitu disakralkan masyarakat Bayan.

\section{Daftar Pustaka}

Agel, Kak. 2003. Kidung Dewa Yadna. Badung: Widyasaba.

Barthes, Roland. 1983. Mythologies. New York: Hill and Wang.

Capra, Fritjof, 1984. The Tao of Physics.New York: Bantam Books.

Djohan, 2010. Respon Emosi Musikal. Bandung : Lubuk Agung.

Fealy, Barton, Greg and Greg, 1981. 'Nahdlatul Ulama, Traditional Islam and Modernity in Indonesia. Australia: Monas Asia Institute.

Lund, C. 1981. World Archaeology 12, New York: Samuel Weiser. 
McCann, Mary Bassano, John Beaulieu dan David, 2015. Terapi Musik dan Warna. Yogyakarta : Araska Publisher.

Nakagawa, Shin. 2000. Musik dan Kosmos Sebuah Pengantar Etnomusikologi. Jakarta: Yayasan Obor Indonesia.

Senen, I Wayan. 2015. Bunyi - bunyian dalam Upacara Keagamaan Hindu di Bali. Yogyakarta: Badan Penerbit ISI Yogyakarta.

\section{Narasumber}

Inan Gending Inaq Mutringen, 90 tahun, Seniman, Desa Adat Senaru, Kecamatan Bayan, Kabupaten Lombok Utara.

Jero Gamel Anggalip, 86 tahun, Seniman dan Peternak, Desa Telaga Banyaq, Kecamatan Bayan, Kabupaten Lombok Utara.

Jero Gamel Nyakranom, 93 tahun, Seniman, Desa Adat Senaru, Kecamatan Bayan, Kabupaten Lombok Utara.

Kake Sutyadi, 28 tahun, Petani, Desa Adat Karang Bajo, Kecamatan Bayan Kabupaten Lombok Utara.

Ma Lokaq Pande, 80 tahun, Tetua Adat, Desa Adat Karang Bajo, Kecamatan Bayan, Kabupaten Lombok Utara.

Ma Lokaq Walin Gumi, 70 tahun, Tetua Adat, Desa Adat Trantapan, Kecamatan Bayan, Kabupaten Lombok Utara.

Penghulu Adat Agung, 58 tahun, Tetu Adat, Desa Adat Bayan, Kecamatan Bayan, Kabupaten Lombok Utara. 